\title{
MUWS (Microbiology in Urban Water Systems) - an interdisciplinary approach to study microbial communities in urban water systems
}

\author{
P. Deines ${ }^{1,2,3}$, R. Sekar ${ }^{1,2,3}$, H. S. Jensen ${ }^{1,2,3}$, S. Tait ${ }^{4}$, J. B. Boxall ${ }^{2}$, A. M. Osborn ${ }^{3}$, and C. A. Biggs ${ }^{1}$ \\ ${ }^{1}$ ChELSI Institute, Pennine Water Group, Department of Chemical and Biological Engineering, \\ The University of Sheffield, UK \\ ${ }^{2}$ Pennine Water Group, Department of Civil and Structural Engineering, The University of Sheffield, UK \\ ${ }^{3}$ Department of Animal and Plant Sciences, The University of Sheffield, Sheffield, UK \\ ${ }^{4}$ Pennine Water Group, School of Engineering Design and Technology, The University of Bradford, Bradford, UK
}

Received: 11 December 2009 - Published in Drink. Water Eng. Sci. Discuss.: 22 January 2010 Revised: 23 June 2010 - Accepted: 1 July 2010 - Published: 12 July 2010

\begin{abstract}
Microbiology in Urban Water Systems (MUWS) is an integrated project, which aims to characterize the microorganisms found in both potable water distribution systems and sewer networks. These large infrastructure systems have a major impact on our quality of life, and despite the importance of these systems as major components of the water cycle, little is known about their microbial ecology. Potable water distribution systems and sewer networks are both large, highly interconnected, dynamic, subject to time and varying inputs and demands, and difficult to control. Their performance also faces increasing loading due to increasing urbanization and longer-term environmental changes. Therefore, understanding the link between microbial ecology and any potential impacts on short or long-term engineering performance within urban water infrastructure systems is important. By combining the strengths and research expertise of civil-, biochemical engineers and molecular microbial ecologists, we ultimately aim to link microbial community abundance, diversity and function to physical and engineering variables so that novel insights into the performance and management of both water distribution systems and sewer networks can be explored. By presenting the details and principals behind the molecular microbiological techniques that we use, this paper demonstrates the potential of an integrated approach to better understand how urban water system function, and so meet future challenges.
\end{abstract}

\section{Introduction}

\subsection{The challenges}

Urban water systems (e.g. drinking water distribution and sewers networks, wetlands and urban rivers) are important for millions of people living in urban areas. They are major components of the water cycle and present unique challenges; the systems are large, complex, highly interconnected and dynamic, with variable hydraulics, input sources and behaviour. These large infrastructure systems have a major impact on people's quality of life by preventing serious disease, protecting/enhancing the environment and reducing flood damage to other infrastructure, thus enabling economic

Correspondence to: C. A. Biggs

(c.biggs@sheffield.ac.uk) and social development. Their overall performance can be evaluated by physical, chemical and biological processes.

Urban water systems throughout Europe face significant new challenges to continue to maintain the provision of safe water supplies, hygienic sanitation and good environmental management against the setting of increased urbanisation, ageing infrastructure and changing climate conditions. These changes are expected to have a negative impact on freshwater resources. The important role of urban water systems has been recognized by the EU with the provision of a series of directives (e.g. Urban Wastewater Treatment, Bathing Waters and Water Framework Directive (WFD)), which govern the use of water in order to provide equitable standards of service and improving environmental protection. Unlike earlier directives, which quantified environmental quality by simple physical and chemical parameters, the WFD aims to ensure that "good ecological status" is attained in all European 
water bodies. It is less prescriptive than previous directives and aims to address the management of the water bodies in a more holistic manner.

\subsubsection{Water distribution systems}

A technological challenge for the EU and worldwide water industry is the continuous delivery of high quality drinking water to customers' taps that meets increasingly stringent standards for aesthetic, bacteriological and chemical water quality. Most distribution systems comprise a complex network of pipes of different ages and material types (UKWIR, 2003). Frequently, each system is supplied from a number of different treatment works each with different source water and treatment systems. Despite the fact that modern water treatment works produce high quality water as it enters the distribution system, the quality of the water is known to deteriorate during transportation within the system (e.g. Furtado et al. (1998) found 7 out of the 10 intestinal disease outbreaks reported in a 3 year study, arose due to contamination occurring within the distribution network). Changes in water quality are due to distribution systems acting as large bio-chemical reactors in which many complex, dynamic, and interrelated hydrodynamic and biochemical processes occur. Water distribution systems harbour microbial consortia, for example, anaerobic bacteria, protozoa, together with meioand macro-fauna such as copepods and nematodes (Evins, 2004; Berry et al., 2006). Additionally the presence of pathogenic bacteria, that are normally undetectable by traditional culture based methods, can represent a potential reservoir for disease outbreaks or long-term illness (Szewzyk et al., 2000).

\subsubsection{Sewer systems}

A recent study in the UK indicated that if no remedial measures were adopted, the discharge of excess volumes from sewer systems during rain fall events to the environment could increase by up to $250 \%$ based on expected climate and urbanization changes (Evans et al., 2004), therefore increasing their future environment impact. Recent studies have also provided strong evidence that sewer flow quality can be strongly influenced by microbiological activity within sewer deposits (Tait et al., 2003). In cases of system failure, the discharge of untreated wastewater and sediments can degrade the water quality of the receiving water body, and may also be a risk to public health. In this respect the microorganisms released with the wastewater may be particularly important, due to the potential release of pathogens. In addition to these acute risks, the activity of the microorganisms in sewers changes the composition of the wastewater. This can, for example, lead to septic wastewater, which is associated with problems such as the formation of toxic gases and malodorous gases; the first posing an acute risk for sewer workers, the latter affecting the public perception of the sewers (HvitvedJacobsen, 2002).

\subsection{The interdisciplinary approach}

Answers to key questions, such as "which microorganisms are present?", "what are they doing?", and "how can we use their outputs and manage their activity to achieve better system outcomes?" are important for understanding the physical, chemical and biological interactions in urban water systems. The long term objective of the project "Microbiology in Urban Water Systems (MUWS)" is to assess the impact of microorganisms, due to their presence, diversity and response to various environmental conditions on aspects of system performance within drinking water distribution systems and sewer networks. Using the research expertise of civil- biochemical engineers and molecular microbial ecologists, the MUWS project aims to address these key questions across different length scales of the urban water systems. Combining engineering and biolgoical disciplines to address environmental engineering challenges is not necessarily a new concept, and has been discussed previously (e.g. Daims et al., 2006; Rittmann et al., 2006; McMahon et al., 2007), however these studies primarily focus on biotechnology/treatment type processes, whereas an interdisciplinary approach to study urban water infrastructure systems has received far less attention. The aim of this paper is to describe the work carried out in the MUWS project so far to permit the application of advanced microbial methods specifically in drinking water distribution systems and sewer networks, thus highlighting the potential of our integrated approach.

\section{Methods}

In the MUWS project, variations in the microbial community of drinking water distribution systems and sewer networks are characterized by using molecular microbiological techniques, rather than culture based techniques. The culture based techniques are currently used by the water industry for evaluation of the performance of the urban water systems. The molecular microbiological techniques, which have previously been successfully applied to freshwater and marine plankton samples, sediments and soil samples (Gelsomino et al., 1999; Moeseneder et al., 1999; Wagner et al., 2003; Smalla et al., 2007) are further developed specifically for the analysis of drinking water, wastewater, biofilms and sewer sediment microbial communities (Fig. 1). In this section we introduce two key methods. The data obtained from these methods has allowed us to gain insight into how a microbial community changes under different conditions at a variety of scales within urban water systems. 


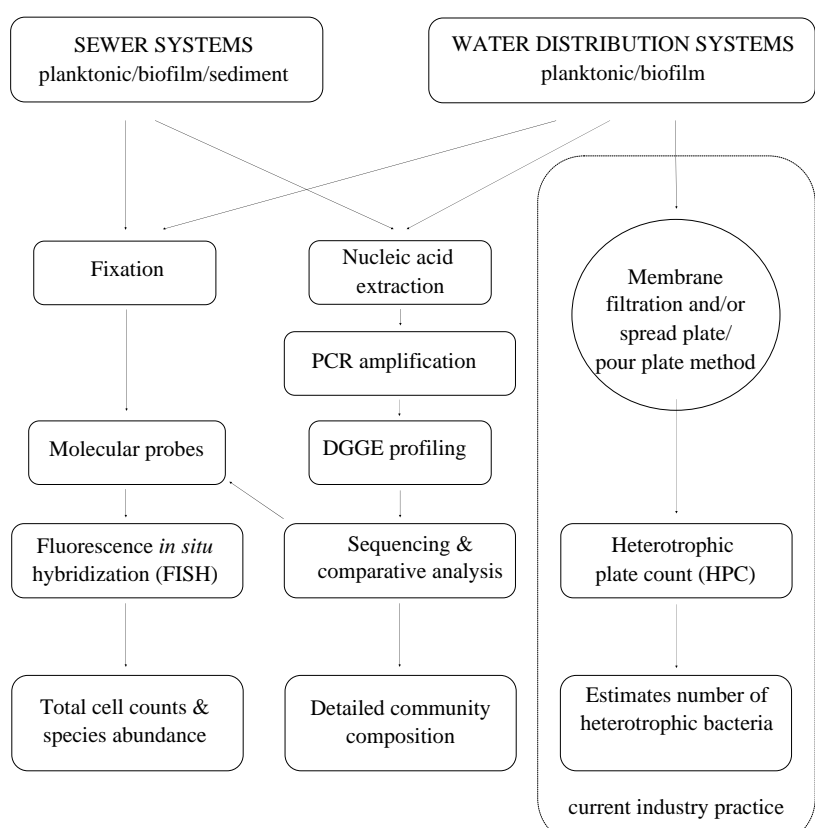

Figure 1. Scheme for the major steps in the molecular analysis of bacterial communities from water distribution and sewer systems and the respective results obtained. In comparison, the right hand side shows the current procedure for monitoring water quality.

\subsection{Denaturing gradient gel electrophoresis (DGGE)}

DGGE analysis (Muyzer et al., 1993) can be used to investigate mixed microbial communities from various environments. The method is based on the molecular separation of DNA fragments when migrating through a DGGE gel, which results in a specific banding pattern. Each individual discrete band refers to a unique "sequence type" or phylotype (van Hannen et al., 1999) which can further be analyzed by sequencing for taxonomic identification. The similarities between banding patterns from different samples can then be analyzed using multivariate analysis such as cluster analysis (Fromin et al., 2002). To demonstrate the DGGE profiling technique, the method was applied to both planktonic samples from a drinking water distribution system and sewer biofilms. The key steps are outlined in Fig. 1 with specific detail relating to the individual samples listed below.

\subsubsection{Drinking water}

Planktonic samples were collected from a water distribution system (domestic cold water tap) in Sheffield in February 2008. Water samples, rather than biofilms, were collected for the drinking water distribution system to provide direct comparison with the culture based methods currently used by water companies. In brief, after a $1 \mathrm{~min}$ flush, water samples $(3 \times 2 \mathrm{~L})$ were collected in sterile bottles and transported to the laboratory on ice and processed immediately. Two liters of water was filtered through a $0.22 \mu \mathrm{m}$ polycarbonate membrane filter (diameter $47 \mathrm{~mm}$; Millipore Ltd., UK) and the filters were kept at $-80{ }^{\circ} \mathrm{C}$ until further analysis. The membrane filters were cut in to halves under sterile conditions and placed directly into the bead solution tubes of the MoBio Ultra Clean Soil DNA Isolation Kit (Cambio Ltd., Cambridge, UK). The DNA was extracted as per the manufacturer's protocol and then used for polymerase chain reaction (PCR) amplification of 16S rRNA genes (Saiki et al., 1988). A direct-PCR, nested-PCR approach was used for comparative analysis of the culture independent drinking water samples. After performing all the DNA extractions, 16S rRNA gene fragments were amplified by direct-PCR, using the universal bacterial primers 338F with a GC-clamp and 530R (Whiteley and Bailey, 2000). For the same water samples, a first round PCR was performed with the bacterial primers $27 \mathrm{~F}$ and 1492R (Lane, 1991) followed by a second PCR amplification using the primers mentioned above. This approach is called nested-PCR and it can improve the sensitivity of the PCR.

For the cultivation-dependent approach one half of individual membrane filters were sonicated in R2A medium (Reasoner and Geldreich, 1985) and $100 \mu \mathrm{l}$ of those samples were used to inoculate $50 \mathrm{ml}$ of R2A medium and cultured at $20^{\circ} \mathrm{C}$ for $48 \mathrm{~h}$. Two $\mathrm{ml}$ of the culture were used for DNA extraction as described above. After performing all the extractions, 16S rRNA gene fragments were amplified by directPCR, using the universal bacterial primers $338 \mathrm{~F}$ with a GCclamp and 530R as mentioned above.

The PCR products were then loaded on an $8 \%$ polyacrylamide gel with a denaturant gradient ranging from 40 to 70\%. DGGE analysis was performed using the Bio-Rad DCode System (Bio-Rad, Hertfordshire, UK). The gel was run at $100 \mathrm{~V}$ at $60^{\circ} \mathrm{C}$ for $16 \mathrm{~h}$ in $1 \mathrm{x}$ TAE (Tris-AcetateEDTA) running buffer and the gels were stained with SYBR Gold prior to image acquisition.

\subsubsection{Sewer biofilms}

Sewer biofilms were collected from two different sewer systems, one in Nantes (France) and the other in Frejlev (Denmark). Two sampling sites were used in Nantes and one site in Frejlev. Two sewer systems were chosen to demonstrate the applicability of the molecular techniques across spatial variability in sewer networks. The sampling site at Frejlev is run by the Environmental Engineering Group at Aalborg University. The samples were recovered from a $300 \mathrm{~mm}$ diameter combined sewer that served an 87 ha catchment with mainly residential inputs. The samples are collected downstream of the town of Frejlev. The site was established as a research station in 1996. The sampling sites in Nantes, France are run by the LCPC, Division Eau et Environnement, Bouguenais, France. The samples were collected from two sites, in combined sewers, located in the central part of Nantes. Both sites were positioned in large 
egg-shaped collectors and are part of ongoing studies carried out by LCPC. Sewer biofilm samples were collected in Nantes in November 2008 and in Frejlev in February 2009. All samples were collected in triplicates.

The biofilm samples were scraped off the sewer pipe surfaces directly above the waterline using sterile $15 \mathrm{ml} \mathrm{Fal-}$ con tubes. The samples were stored at $-20^{\circ} \mathrm{C}$ until further processing. DNA was extracted from $0.2 \mathrm{~g}$ (wet weight) of biofilms using the same DNA isolation kit as mentioned above for drinking water. To minimize interference with humic substances DNA extracts were diluted (1:10) before performing PCR amplifications. For the amplification of $16 \mathrm{~S}$ rRNA gene fragments, the same primer pair with the GCclamp as mentioned above was used (direct-PCR approach). PCR products were visualized by gel electrophoresis followed by ethidium bromide staining to ensure that the correct size fragment was amplified. DGGE analysis of the PCR fragments was performed as described above for the drinking water samples.

\subsection{Fluorescence in situ hybridization (FISH)}

FISH with rRNA-targeted oligonucleotide probes is used for detection and quantification of microorganisms without prior cultivation (Amann et al., 1995). The method has been applied widely to different environmental samples including drinking water systems (Manz et al., 1993). To overcome problems of low detection limit and fluorescence intensity faced in oligotrophic environmental samples (such as drinking water), we have optimized and applied the CARD-FISH (catalysed reported deposition-fluorescence in situ hybridization) method. This method was originally developed for studying bacterioplankton in marine samples (Pernthaler et al., 2002). Again to demonstrate the technique the planktonic samples from a drinking water distribution system and sewer biofilms were analysed using CARD-FISH (Fig. 1).

\subsubsection{Drinking water}

The water samples $(50 \mathrm{ml})$ were fixed in $2 \%(\mathrm{v} / \mathrm{v})$ final concentration of formalin for less than $24 \mathrm{~h}$. The samples were then filtered on to $0.22 \mu \mathrm{m}$ pore size white polycarbonate membrane filters (diameter $47 \mathrm{~mm}$, Millipore Ltd., UK) and stored at $-20^{\circ} \mathrm{C}$ until further processing. The samples were permeabilised with lysozyme and achromopeptidase as described previously (Pernthaler et al., 2002; Sekar et al., 2003). The hybridization was done with the HRP labeled eubacterial oligonucleotide probes (EUB338). The hybridization, washing and tyramide signal amplification with FITClabeled tyramides were done as per the protocol described in Pernthaler et al. (2002). The preparations were counterstained with the DNA specific fluorescent stain, DAPI, and observed under an Olympus BX51 epifluorescence microscope (Olympus Ltd., UK). The images (30 per triplicate sample) were captured using CellB imaging software (Olym-

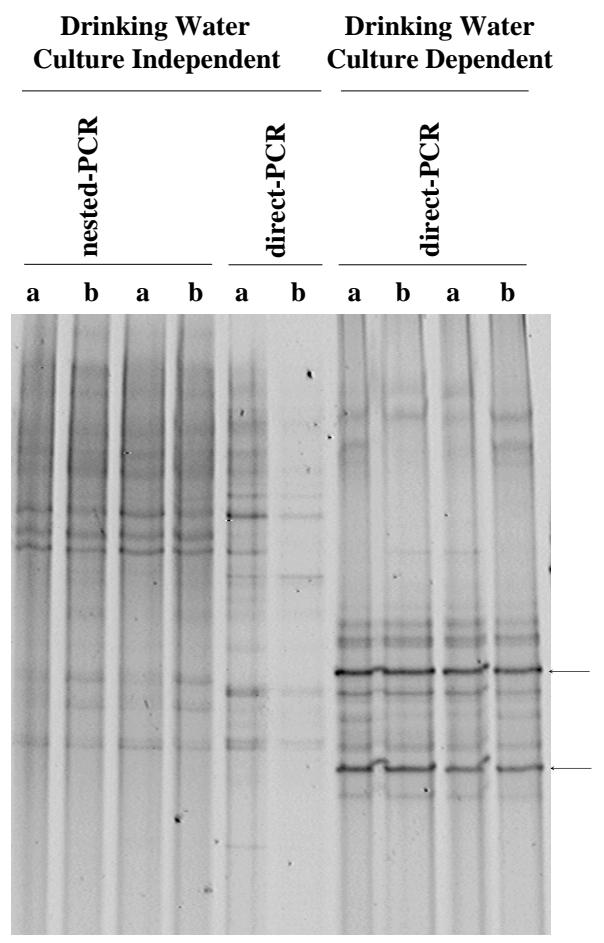

Figure 2. DGGE profiles of PCR-amplified 16S rRNA gene fragments derived from direct- and nested-PCR approach for culture independent drinking water samples, and a direct-PCR approach for culture dependent drinking water samples. Arrows indicate the two dominant phylotypes present using the culture dependent approach. "a" and "b" refer to biological replicates.

pus Ltd., UK). Quantification of cell numbers of the drinking water samples was performed by imaging and counting the DAPI stained cells.

\subsubsection{Sewer biofilms}

Triplicate sewer samples were fixed either with $2 \%(\mathrm{v} / \mathrm{v})$ formalin or 1:1 PBS/Ethanol on the day of sampling. The sewer biofilm samples collected from France and Denmark were gently vortexed, mixed with low gelling agarose $(0.2 \% \mathrm{w} / \mathrm{vol})$ and $10 \mu \mathrm{l}$ of the samples were pipetted into the wells of a standard type multi-well Epoxy slide (Carl Roth $\mathrm{GmbH}+\mathrm{Co}$, Karlsruhe, Germany). The permeabilization, hybridization with the eubacterial probes (EUB338) and the tyramide signal amplification was done as described above for the water samples. The preparations were observed under an epifluorescence microscope as described above. 


\section{Results and discussion}

\subsection{Bacterial community profiling of drinking water samples}

Figure 2 shows the DGGE patterns for drinking water samples based on a culture-independent and culture dependent approach. The differences in DGGE patterns of the directPCR approach for both samples show that with the culturedependent approach we target a specific bacterial community that responds to the imposed enrichment. One would conclude from Fig. 2, that by using the culture-dependent approach, two phylotypes dominate the bacterial community in the drinking water collected. (NB: Often the brightest bands in the profile represent the dominant members of the community, but be aware of potential biases (Forney et al., 2004)).

This is significant as one method that is widely used to assess the general microbial water quality of drinking water by water distributors is the cultivation-dependent method of heterotrophic plate counts (HPCs) (see Sartory, 2004). The method is highly variable since the cultivation medium, incubation temperature, incubation time, origin, season of the year, and age of the water sample have a significant effect on the fraction of the total bacterial cells that grow and hence will be detected (Allen et al., 2004). Despite the discrepancy between total bacterial concentrations and cultivable cell concentrations (HPCs) in aquatic samples as shown by Staley and Konopka (1985), HPCs are still used for routine monitoring applications in a quantitative way (Standard Methods for the Examination of Water and Wastewater, 20th Edn.). Pepper et al. (2004), for example, quantified the concentration of HPC bacteria within water from the source to the consumer's tap. Their study showed that the number of HPC bacteria increased dramatically from the distribution system to the consumers tap, but they did not quantify whether the bacterial community changed as well. There are only a few studies providing qualitative data about the HPC community composition and/or population dynamics (e.g. Kalmbach et al., 1997; Norton and LeChevallier, 2000).

For the enumeration of bacteria in drinking water, lownutrient media are commonly used such as R2A (Reasoner and Geldreich, 1985). It was designed specifically as a lownutrient, low-ionic strength formulation to isolate bacteria that have a water-based lifestyle (Reasoner, 1990). Our results support previous observations that media used for HPC are selective for those bacteria that can grow under the specific conditions used. Comparing these results to the DGGE profiles of either direct- or nested-PCR approach (no cultivation step involved) reveals considerable differences in the banding pattern observed. Several unique bands that were not visible in the culture dependent approach were seen, supporting that the culture dependent method underestimated the number of phylotypes present in the sample and that when the culture dependent method is used for assessment of microbial contamination in drinking water distribution systems

\section{Sewer biofilms}

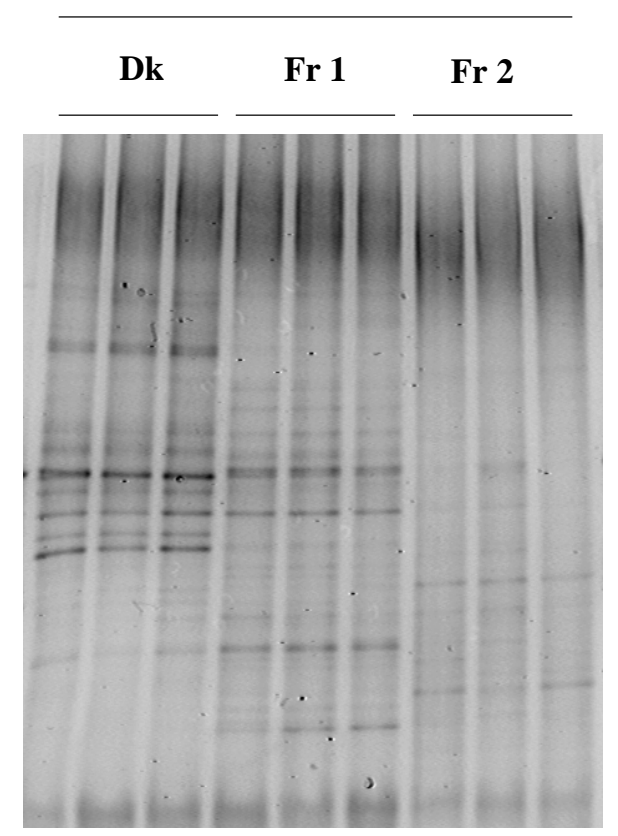

Figure 3. DGGE profiles of PCR-amplified 16s rRNA gene fragments derived from direct-PCR approach for sewer biofilm samples from one site in Denmark (Dk) and two sampling sites in France (Fr1, Fr2).

there is a significant risk that microbial contaminations can exist but cannot be detected with current practice.

Figure 2 shows that differences can be seen between the nested-PCR approach, which includes an additional PCR step, and the direct-PCR approach. Bands that appear at the same position have changed their intensity and new bands become visible. Therefore, in certain cases the nested-PCR approach may need to be applied to increase sensitivity and to complete the overall presentation of the taxonomic diversity present in the sample.

\subsection{Bacterial community profiling of sewer biofilm samples}

Figure 3 shows the DGGE profiling for a sampling site from Denmark and two sites from France. A total of 26 discrete bands were detected on the gel. A total of 18 bands were present in the samples from Denmark where as 19 and 9 bands were found in France sampling site 1 and 2, respectively. This analysis suggests similar levels of diversity (although not necessary the same composition) between sewer biofilms from Denmark and France sampling site 1; and that sampling site 2 in France showed lower diversity. The overall results indicate that 4 bands were common to all three sites and 12 were found in two sites and 10 were unique to one site. Identification of common bands (and further taxonomic 

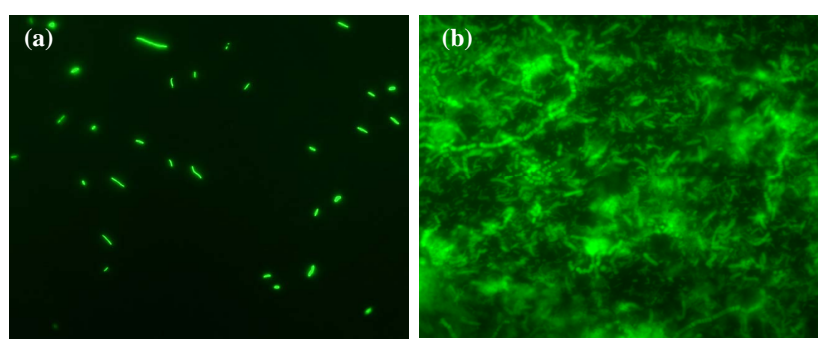

Figure 4. Photomicrographs of drinking water bacterioplankton (a) and sewer biofilm bacteria (b) hybridized with eubacterial probes.

identification) could be used to identify indicator microorganisms that are present across diverse spatial distributions within the sewer networks. Unique bands can also be used for fingerprinting microorganisms related to distinctive networks, or spatial distribution within the network if comparison between effluent, biofilm and sediment samples is made.

Hence the DGGE technique can be used to monitor changes in bacterial communities within urban water systems, taking spatial and temporal variation into account (see Fig. 1). This variability can be investigated in terms of differences in the presence or absence of specific bands and/or in changes in their relative abundance (band intensity). Clustering techniques can be applied to identify samples, which generate similar patterns (Boon et al., 2002). Multivariate analysis also allows the interpretation of DGGE patterns in relation to environmental variables (e.g. McCaig et al., 2001). Hence, when conducted in combination with relevant physical and chemical measurements, DGGE provides the opportunity to study the changes in microbial diversity relevant to conditions within the urban water system.

\subsection{FISH of microorganisms in drinking water and sewer biofilms}

In this study, we have applied CARD-FISH methods to detect and quantify the microorganisms in drinking water (Fig. 4a), and sewer biofilms (Fig. 4b). The CARD-FISH images, with the eubacterial probes, provide an opportunity to quantify the number of bacteria within the water samples (Fig. 4a). Unlike HPC however, this technique is not based on a prior basis of culturable bacteria. Counter staining the samples with a DNA stain like DAPI (results not shown), confirms that CARD-FISH is able to detect, and therefore confidently account for, more than 90 to $93 \%$ of the bacteria present in drinking water sample. Hence the CARD-FISH method provides more confidence in enumerating the number of bacteria in water samples over the routinely used HPC method. Another new rapid and reliable method for cell enumeration of drinking water has also been developed based on flow cytometry (Berney et al., 2008; Hammes et al., 2008; Siebel et al., 2008) and is already being routinely used by the Zurich Waterworks (Egli et al., 2008).

Figure $4 \mathrm{~b}$ demonstrates the application of CARD-FISH for sewer biofilms collected from France. Whilst it is not possible to easily count the number of cells that are present in the biofilm, as found with Fig. 4a, the CARD-FISH method with eubacterial probes enables the morphology of the biofilm to be visualized. Comparison of CARD-FISH images across spatial and or temporal samples could therefore provide insight into the morphological development of biofilms within urban water systems.

An added functionality of CARD-FISH is the ability to target specific microorganisms (see Fig. 1) which will reveal the abundance of different phylogenetic or functional bacterial and other microbial groups within biofilms or water samples. CARD-FISH in combination with epifluorescence microscropy or confocal laser scanning microscopy and digital image analysis can be combined into quantitative polyphasic approach to study the microbes in urban water systems. Microorganisms in the source water, drinking water, wastewater and in biofilms can be studied as well as their seasonal and successional changes. Particularly, the CARDFISH technique is very suitable for studying bacteria (and other microbes) in highly oligotrophic environments such as water distribution systems because of their increased sensitivity and fluorescence intensity. In combination with microautoradigraphy (MAR) or stable isotope probing (SIP), this will provide both structural and functional characteristics of targeted microorganisms (Teira et al., 2004; Sintes and Herndl, 2006; Wagner et al., 2006).

\section{Future interdisciplinary approach}

The aim of this paper was to present a conceptual outline to water practitioners on the types of culture independent molecular microbiological techniques available, and the level of information achievable from these techniques, when applied to urban water systems. Through this, we aimed to show the benefits of a partnership with microbial ecologists, specifically looking at urban water infrastructure, as better quantification of bacterial communities and their temporal or spatial changes in urban water systems, through an integrated approach will lead to further understanding of their associated biological processes.

The benefit of an interdisciplinary approach comes in a variety of different aspects. For example, existing engineering knowledge and/or computer models can provide insight into choosing the most appropriate sampling locations within drinking water distribution systems or sewer networks that enable specific research questions to be addressed e.g. influence of spatial or temporal changes on systems performance due to changes in microbial diversity. Sampling protocols across the different disciplines also need to be integrated to ensure the safe collection of representative samples within 


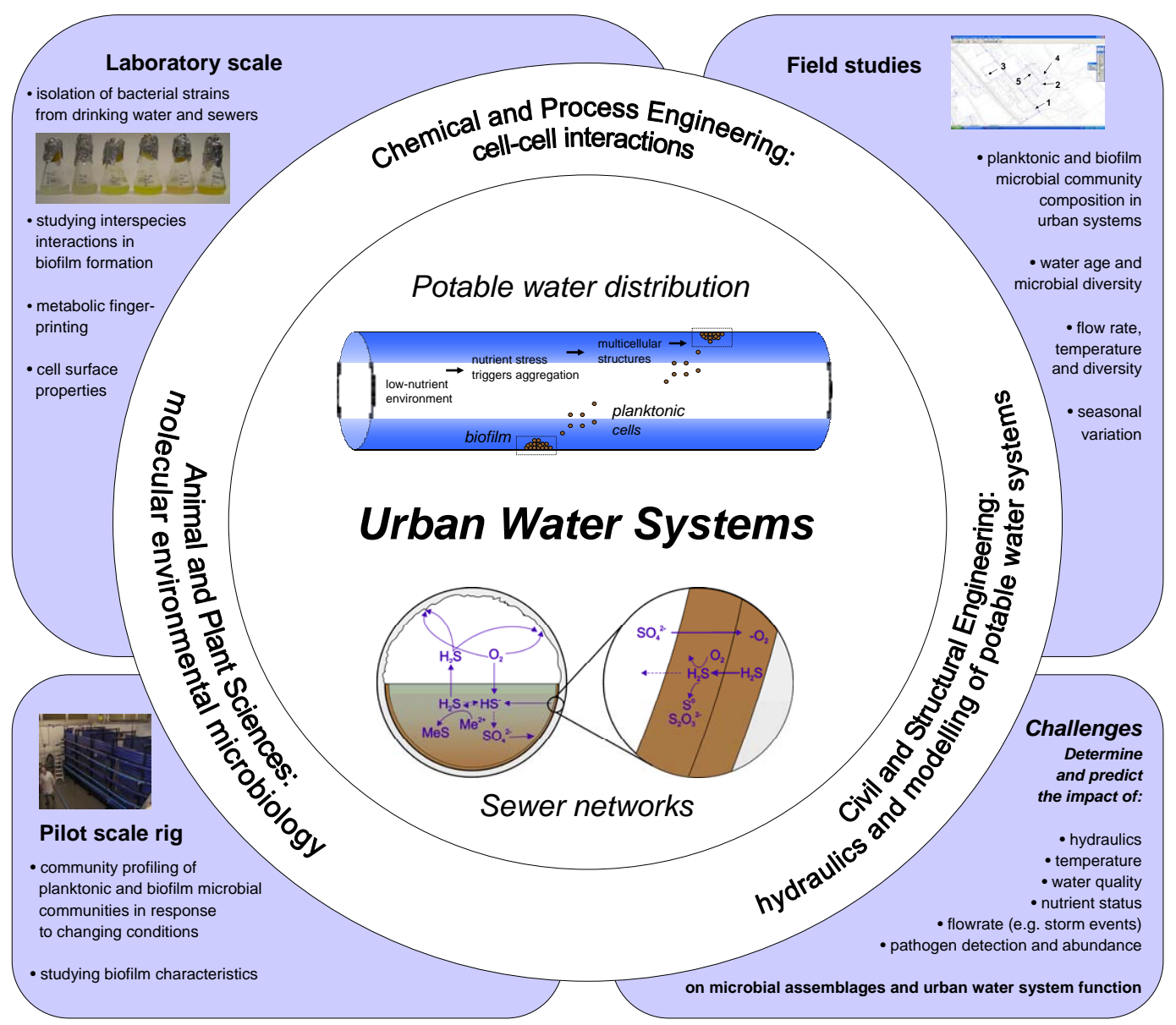

Figure 5. Overview of the MUWS (Microbiology in Urban Water Systems) project showing the challenges, the approaches and the different departments involved.

the urban water system in terms of both biological reproducibility as well as engineering relevance.

Also, in an integrated approach, molecular microbiological analysis of water and biofilm/sediment samples, as presented here, should be conducted at the same time as the measurement of the physical and chemical properties of urban water systems. Multivariate analysis of the different parameters, will then allow future interpretation of changes in biological diversity to specific environmental variables, hydraulic conditions etc. This will provide the fundamental knowledge to ultimately develop "biological" management tools that will aid system operators to achieve improved levels of environmental and public health protection without resorting to the need for additional infrastructure or energy intensive treatment processes. To achieve this, the MUWS project specifically operates across the length scales from laboratory to pilot and field studies (Fig. 5) and draws on the expertise of civil-, biochemical engineers and molecular microbial ecologists to address key challenges. This interdisciplinary and multi-scale approach provides a unique opportunity to develop and understand relationships between the presence and behaviour of microbial assemblages and their potential release into the environment, with asset characteristics, operation (hydraulics and cleaning/disinfection regimes) and water quality (i.e. linking biological function with engineering performance).

Acknowledgements. Funding was provided by FP6 EU Marie Curie Transfer of Knowledge programme (No. 42444). CAB also thanks the EPSRC for the provision of an Advanced Research Fellowship (EP/E053556/01) and ChELSI funding (GR/S84347/01). The authors are grateful to Professor Vollertsen at Aalborg University, Denmark and Dr Larrarte at LCPC, Division Eau et Environnement, Bouguenais, France, for biofilm samples. They also thank Professor Amann, Max Planck Institute for Marine Microbiology, Germany, for providing FISH probes.

Edited by: J. Vreeburg 


\section{References}

Allen, M. J., Edberg, S. C., and Reasoner, D. J.: Heterotrophic plate count bacteria - what is their significance in drinking water? Int. J. Food Microbiol., 92, 265-274, 2004.

Amann, R. I., Ludwig, W., and Schleifer, K. H.: Phylogenetic identification and in-situ detection of individual microbial-cells without cultivation, Microbiol. Rev., 59, 143-169, 1995.

Berney, M., Vital, M., Hülshoff, I., Weilenmann, H. U., Egli, T., and Hammes, F.: Rapid, cultivation-independent assessment of microbial viability in drinking water, Water Res., 42, 4010-4018, 2008..

Berry, D., Xi, C.W., and Raskin, L.: Microbial ecology of drinking water distribution systems, Curr. Opin. Biotech., 17, 297-302, 2006.

Boon, N., De Windt, W., Verstraete, W., and Top, E. M.: Evaluation of nested PCR-DGGE (denaturing gradient gel electrophoresis) with group-specific $16 \mathrm{~S}$ rRNA primers for the analysis of bacterial communities from different wastewater treatment plants, FEMS Microbiol. Ecol., 39, 101-112, 2002.

Daims, H., Taylor, W. M., and Wagner, M.: Wastewater treatment: a model system for microbial ecology, Trends Biotechnol., 24, 483-489, 2006.

Egli, T., Berney, M., Hammes, F., and Füchslin, H. P.: New methods for assessing the safety of drinking water, in: EAWAG News 65, From source to tap - good quality drinking water for today and tomorrow, 20-23, 2008.

Evans, E., Ashley, R. M., Hall, J., Renning-Rowsell, E., Saul, A., Sayers, P., Thorne, C., and Watkinson, A.: Foresight Future Flooding Scientific Summary, Vol. 1, Future Risks and their Drivers, Office of Science and Technology, London, UK, 2004.

Evins, C.: Small animals in drinking-water distribution systems, in: Safe Pipe Water: Managing Microbial Water Quality in Piped Distribution Systems, edited by: Ainsworth, R., World Health Organization, IWA Publishing, London, UK, 2004.

Forney, L. J., Zhou, X., and Brown, C. J.: Molecular microbial ecology: land of the one-eyed king, Curr. Opin. Microbiol., 7, 210-220, 2004.

Fromin, N., Hamelin, J., Tarnawski, S., Roesti, D., JourdainMiserez, K., Forestier, N., Teyssier-Cuvelle, S., Gillet, F., Aragno, M., and Rossi, P.: Statistical analysis of denaturing gel electrophoresis (DGE) fingerprinting patterns, Environ. Microbiol., 4, 634-643, 2002.

Furtado, C., Adak, G. K., Stuart, J. M., Wall, P. G., Evans, H. S., and Casemore, D. P.: Outbreaks of waterborne infectious intestinal disease in England and Wales, 1992-95, Epidemiol. Infect., 121, 109-119, 1998.

Gelsomino, A., Keijzer-Wolters, A.C., Cacco, G., and Van Elsas, J. D.: Assessment of bacterial community structure in soil by polymerase chain reaction and denaturing gradient gel electrophoresis, J. Microbiol. Meth., 38, 1-15, 1999.

Hammes, F., Berney, M., Wang, Y., Vital, M., Köster, O., and Egli, T.: Flow-cytometric total bacterial cell counts as a descriptive microbiological parameter for drinking water treatment processes, Water Res., 42, 269-277, 2008.

Hvitved-Jacobsen, T.: Sewer Processes - Microbial and Chemical Process Engineering of Sewer Networks, CRC Press, 1st Edn., Boca Raton, Florida, USA, 2002.

Kalmbach, S., Manz, W., and Szewzyk, U.: Isolation of new bac- terial species from drinking water biofilms and proof of their in situ dominance with highly specific $16 \mathrm{~S}$ rRNA probes, Appl. Environ. Microb., 63, 4164-4170, 1997.

Lane, D. J.: 16S/23S rRNA sequencing, in: Nucleic Acid Techniques in Bacterial Systematics, edited by: Stackebrandt, E. and Goodfellow, M., Wiley, London, UK, 115-175, 1991.

Manz, W., Szewzyk, U., Ericsson, P., Amann, R., Schleifer, K. H., and Stenström, T. A.: In situ identification of bacteria in drinking water and adjoining biofilms by hybridization with $16 \mathrm{~S}$ and $23 \mathrm{~S}$ rRNA-directed fluorescent oligonucleotide probes, Appl. Environ. Microb., 59, 2293-2298, 1993.

McCaig, A. E., Glover, L. A., and Prosser, J. I.: Numerical analysis of grassland bacterial community structure under different land management regimens by using $16 \mathrm{~S}$ ribosomal DNA sequence data and denaturing gradient gel electrophoresis banding patterns, Appl. Environ. Microb., 67, 4554-4559, 2001.

McMahon, K. D., Garcia Martin, H., and Hugenholtz, P.: Integrating ecology into biotechnology, Curr. Opin. Biotech., 18, 287292, 2007.

Moeseneder, M. M., Arrieta, J. M., Muyzer, G., Winter, C., and Herndl, G. J.: Optimization of terminal-restriction fragment length polymorphism analysis for complex marine bacterioplankton communities and comparison with denaturing gradient gel electrophoresis, Appl. Environ. Microb., 65, 3518-3525, 1999.

Muyzer, G., Dewaal, E. C., and Uitterlinden, A. G.: Profiling of complex microbial-populations by denaturing gradient gelelectrophoresis analysis of polymerase chain reaction-amplified genes-coding for $16 \mathrm{~S}$ ribosomal-RNA. Appl. Environ. Microb., 59, 695-700, 1993.

Norton, C. D. and LeChevallier, M. W.: A pilot study of bacteriological population changes through potable water treatment and distribution, Appl. Environ. Microb., 66, 268-276, 2000.

Pepper, I. L., Rusin, P., Quintanar, D. R., Haney, C., Josephson, K. L., and Gerba, C. P.: Tracking the concentration of heterotrophic plate count bacteria from the source to the consumer's tap, Int. J. Food Microbiol., 92, 289-295, 2004.

Pernthaler, A., Pernthaler, J., and Amann, R.: Fluorescence in situ hybridization and catalyzed reporter deposition for the identification of marine bacteria, Appl. Environ. Microb., 68, 3094-3101, 2002.

Reasoner, D. J.: Monitoring heterotrophic bacteria in potable water, in: Drinking Water Microbiology: Progress and Recent Developments, edited by: McFeters, G. A., Springer, New York, USA, 453-477, 1990.

Reasoner, D. J. and Geldreich, E. E.: A new medium for the enumeration and subculture of bacteria from potable water, Appl. Environ. Microb., 49, 1-7, 1985.

Rittmann, B. E., Hausner, M., Löffler, F., Love, N. G., Muyzer, G., Okabe, S., Oerther, D. B., Peccia, J., Raskin, L., and Wagner, M.: A vista for microbial ecology and environmental biotechnology, Environ. Sci. Technol., 40, 1096-1103, 2006.

Saiki, R. K., Gelfan, D. H., Stoeffel, S., Scharf, S. J., Higuchi, R., Horn, G. T., Mullis, K. B., and Erlich, H. A.: Primer-directed enzymatic amplification of DNA with a thermostable DNA polymerase, Science, 239, 487-491, 1988.

Sartory, D. P.: Heterotrophic plate count monitoring of treated drinking water in the UK: a useful operational tool, Int. J. Food Microbiol., 92, 297-306, 2004. 
Sekar, R., Pernthaler, A., Pernthaler, J., Warnecke, F., Posch, T., and Amann, R.: An improved protocol for quantification of freshwater Actinobacteria by fluorescence in situ hybridization, Appl. Environ. Microb., 69, 2928-2935, 2003.

Siebel, E., Wang, Y., Egli, T., and Hammes, F.: Correlations between total cell concentration, total adenosine tri-phosphate concentration and heterotrophic plate counts during microbial monitoring of drinking water, Drink. Water Eng. Sci., 1, 1-6, doi:10.5194/dwes-1-1-2008, 2008.

Smalla, K., Oros-Sichler, M., Milling, A., Heuer, H., Baumgarte, S., Becker, R., Neuber, G., Kropf, S., Ulrich, A., and Tebbe, C. C.: Bacterial diversity of soils assessed by DGGE, T-RFLP and SSCP fingerprints of PCR-amplified 16S rRNA gene fragments: Do the different methods provide similar results?, J. Microbiol. Meth., 69, 470-479, 2007.

Sintes, E. and Herndl, G. J.: Quantifying substrate uptake by individual cells of marine bacterioplankton by catalyzed reporter deposition fluorescence in situ hybridization combination with microautoradiography, Appl. Environ. Microb., 72, 7022-7028, 2006.

Staley, J. T. and Konopka, A.: Measurement of in situ activities of nonphotosynthetic microorganisms in aquatic and terrestrial habitats, Annu. Rev. Microbiol., 39, 321-346, 1985.

Szewzyk, U., Szewzyk, R., Manz, W., and Schleifer, K. H.: Microbiological safety of drinking water, Annu. Rev. Microbiol., 54, 81-127, 2000.
Tait, S. J., Ashley, R. M., Verhoeven, R., Clemens, F., and Aanen, L.: Sewer sediment transport studies using an environmentally controlled annular flume, Water Sci. Technol., 47, 51-60, 2003.

Teira, E., Reinthaler, T., Pernthaler, A., Pernthaler, J., and Herndl, G. J.: Combining catalyzed reporter deposition-fluorescence in situ hybridization and microautoradiograph to detect substrate utilization by bacteria and archaea in deep ocean, Appl. Environ. Microb., 70, 4411-4414, 2004.

UKWIR: National database of mains failures 2003, Vol. Report No. Z3/3G/05/7, 2003.

van Hannen, E. J., Zwart, G., van Agterveld, M. P., Gons, H. J., Ebert, J., and Laanbroek, H. J.: Changes in bacterial and eukaryotic community structure after mass lysis of filamentous cyanobacteria associated with viruses, Appl. Environ. Microb., 65, 795-801, 1999.

Wagner, M., Horn, M., and Daims, H.: Fluorescence in situ hybridisation for the identification and characterisation of prokaryotes, Curr. Opin. Microbiol., 6, 302-309, 2003.

Wagner, M., Nielsen, P. H., Loy, A., Nielsen, J. L., and Daims, H.: Linking microbial community structure with function: fluorescence in situ hybridization-microautoradiography and isotope arrays, Curr. Opin. Biotech., 17, 83-91, 2006.

Whiteley, A. S. and Bailey, M. J.: Bacterial community structure and physiological state within an industrial phenol bioremediation system, Appl. Environ. Microb., 66, 2400-2401, 2000. 